\title{
Eye movements and the identification of spatially ambiguous words during Chinese sentence reading
}

\author{
ALBRECHT W. INHOFF and CAILI WU \\ State University of New York, Binghamton, New York
}

\begin{abstract}
Readers of Chinese must generally determine word units in the absence of visually distinct interword spaces. In the present study, we examined how a sequence of Chinese characters is parsed into words under these conditions. Eye movements were monitored while participants read sentences with a critical four-character (C1234) sequence. Three partially overlapping character groupings formed legal words in the ambiguous condition (C12, C23, and C34), two of which corresponded to contextconsistent words (C12 and C34). Two nonoverlapping groupings corresponded to legal words in the control conditions (C12 and C34). In two experiments, readers spent more time viewing the critical character sequence and its two center characters (C23) in the ambiguous condition. These results argue against the strictly serial assignment of characters to words during the reading of Chinese text.
\end{abstract}

All written languages use spatial conventions to determine the ordering of linguistic symbols. In English and other European languages, letters and words are ordered from left to right along horizontal lines of print. Semitic languages order these symbols from right to left, and traditional Chinese script uses a variety of spatial arrangements, so that a sequence of characters can be ordered from left to right, right to left, or top to bottom. Simplification of Chinese script in mainland China included, among other things, the adoption of a standardized character order, from left to right.

The vast majority of modern languages also use spatial cues to form meaning-defining letter groupings. European and Semitic scripts use spatial proximity to aggregate a sequence of letters into a word and to separate successive words by means of visually distinct interword spaces. Since a letter typically denotes a phoneme in these scripts, the spatial extent of a word varies with its phonological, orthographic, and morphological complexity, and text consists of a sequence of words of various lengths.

The spatial grouping of letter sequences into perceptually distinct word units provides substantial benefits. The reading rate for English text decreases dramatically when spaces between words are removed (Fisher, 1976; Malt \& Seamon, 1978; Rayner, Fischer, \& Pollatsek, 1998) or when they are masked (Morris, Rayner, \& Pollatsek, 1989; Pollatsek \& Rayner, 1982). In Fisher's original study, readers spent approximately $250 \mathrm{msec}$ per word when succes-

The work was supported by NIH Grant R01HD043405. We thank Brianna Eiter, George McConkie, and an anonymous reviewer for helpful comments on an earlier version of the manuscript. Correspondence concerning this article should be sent to A.W. Inhoff, Department of Psychology, State University of New York, Binghamton, NY 13902 (e-mail: inhoff@binghamton.edu). sive words of text were separated by spaces, as occurs in normal script, and more than twice that $(550 \mathrm{msec})$ when spaces were removed or filled. When available, interword spaces provide a reader with two sources of effective information: They delineate the spatial extent of words that is used to direct the eyes, and they segment letter sequences into meaning-conveying units.

Evidence for the use of interword spaces for the targeting of eye movements comes from detailed corpus analyses that show that readers direct the eyes toward the spatial center of a to-be-read word (McConkie, Kerr, Reddix, \& Zola, 1988; Radach \& McConkie, 1998; Rayner, 1979), since this appears to be a particularly favorable location for word identification (O'Regan \& Jacobs, 1992). Analogous experimental data show that different spatial formats of the identical compound word lead to different saccade targeting strategies, each of which is designed to reach the center(s) of spatially distinct letter groupings (Inhoff \& Radach, 2002; Inhoff, Radach, Eiter, \& Skelly, 2003).

Interword spaces also delineate orthographic structures that provide access to representations of meaning. Consequently, insertion of blank spaces can benefit reading when it allows one to discern meaning-defining subunits of complex words, even when the insertion of spaces is orthographically illegal (Inhoff, Radach, \& Heller, 2000). ${ }^{1}$ Similarly, English compounds were classified more effectively when they were spatially segmented (e.g., fire station) than when they were unified (firestation; Juhasz, Inhoff, \& Rayner, 2005). Conversely, blank spaces between letters can bring reading to a near standstill when they are inserted randomly into alphabetic text that is otherwise devoid of interword spaces (Epelboim, Booth, \& Steinman, 1994).

As was noted before, Chinese script differs from Roman script and most other scripts in that words are neither spa- 
tially segmented nor linguistically marked - for example, via prefixes and suffixes. Instead, Chinese script molds the strokes and radicals of a character into uniform, approximately square-shaped forms. Each character occupies the same horizontal extent in a passage of text, although the visual and orthographic complexity of characters can differ dramatically. Spaces between characters are relatively small and equidistant, so that Chinese text has the appearance of a relatively homogeneous sequence of square-like shapes (that is occasionally interrupted by punctuation marks). Most Chinese characters can be words on their own, but single-character words are relatively rare in modern text. The majority of words - typically, $70 \%$ to $80 \%$ contain two characters (Yu et al., 1985), and longer words with three or four constituent characters can also occur. There is thus some uncertainty about the spatial extent of a to-be-recognized word.

Recent results show that the absence of visually distinct word unit cues in Chinese influences saccade programming. Even though the perceptual span in Chinese, approximately four to five characters during each eye fixation (Inhoff \& Liu, 1997, 1998), is likely to encompass more than one word unit, readers do not direct their saccades toward the spatial center of the next word in the text (Tsai \& McConkie, 2003; Yang \& McConkie, 1999). Instead, they appear to target characters or move the eyes across a relatively constant spatial area. Readers of Japanese show a corresponding saccade targeting strategy when text is composed entirely of (Chinese) Kanji characters (Kajii, Nazir, \& Osaka, 2001).

The lack of word length cues in Chinese can also impede the success of sentence comprehension under some conditions. In one of their studies, Hsu and Huang (2000b) used sentences with character sequences that could be parsed into different word units. For instance, the first character of the sentence 花生长在屋后的田里, 花, can either form a word on its own (flower) or combine with the next character, 生 (birth), to form a different word, 花生 (peanut). The third character, 长 (growing), does not reveal the intended character-to-word assignment, since characters two and three also form a context-consistent word, 生长 (growing). Control sentences did not contain corresponding parsing ambiguities, and measurement of sentence-reading time showed that participants spent more than twice the time on the reading (aloud) of ambiguous sentences than on the reading of unambiguous control sentences. Critically, insertion of illegal interword spaces that grouped characters into words-for example, 花 生长 在 or 花生 长 在一aided the reading of ambiguous sentences. A similar effect was obtained in an earlier study (Hsu \& Huang, 2000a), where insertion of interword spaces facilitated the reading of difficult sentences.

The benefits of interword spaces were relatively limited, however. Interword spaces did not facilitate the reading of typical sentences that did not contain parsing ambiguities or other difficulties (Hsu \& Huang, 2000a, 2000b). We (Inhoff, Liu, Wang, \& Fu, 1997) obtained similar effects of interword spaces for sentences taken from Chinese news magazines. ${ }^{2}$ Moreover, no cost was incurred from randomly inserted spaces between Chinese characters. To recall, an analogous manipulation with English text rendered fluent reading near impossible (Epelboim et al., 1994). Other findings also indicate that word boundaries are discerned effectively, among them the presence of robust word superiority effects for two-character words in a sentence-reading task (Chen, 1999).

The main goal of the present study was to examine how Chinese readers determine the boundaries of words in the absence of spatial segmentation cues. Two word-boundaryfinding strategies were contrasted: one referred to as the unidirectional parsing hypothesis and one referred to as the multiple activation hypothesis. The unidirectional parsing hypothesis assumes that the character-to-word assignment is strictly sequential, so that one character is assigned to a word at a time and that assignment proceeds strictly according to character order, unidirectionally from left to right for simplified Chinese script. The onset of the ambiguous character sequence in Hsu and Huang's (2000b) experiment, 花生长在, was thus particularly difficult to read, because a unidirectional left-to-rightdirected parsing routine could not determine the identity of the first word - that is, whether it was 花 or 花生.

Similar theoretical conceptions have been proposed for the parsing of lexically ambiguous letter sequences in English (Libben, 1994). In Libben's model, letters of a spatially defined word in English are aggregated from left to right until a meaning-conveying (lexical) unit is found. This strictly unidirectional aggregation is recursive and begins anew when the parsing of the full letter sequence reveals a lexical subunit, until all lexical subunits have been discerned. The letter sequence SEATRIM, for instance, is assumed to be aggregated into SEA and TRIM, then into SEAT and RIM, and then into SEATRIM. The sequential parsing of the structurally similar word with a lexically unambiguous letter sequence, LARKEATER, will reveal only two constituent units, LARK and EATER, thus requiring less parsing. Consistent with this recursive parsing assumption, no responses in a lexical decision task were substantially longer, by more than $120 \mathrm{msec}$, when a pseudoword contained a lexically ambiguous center letter sequence than when it did not. An analogous, strictly unidirectional lexical processing assumption is also a key element of one prominent class of sentence-reading models (Reichle, Pollatsek, Fisher, \& Rayner, 1998; Reichle, Rayner, \& Pollatsek, 2003), according to which the lexical processing of the words in a sentence proceeds in a strict sequential order from one word to the next.

The theoretical alternative, the multiple activation hypothesis, assumes that all Chinese characters within the effective area of vision (the perceptual span) are free to combine into viable word units without directional constraint. A particular character can thus combine with a right- and/or a left-side neighbor. The goodness of a particular character-to-word assignment is then determined by the success with which all the characters within the effective range of vision can be segmented into contextconsistent words. According to the hypothesis, there were two distinct sources of ambiguity in Hsu and Huang's 
(2000b) study, both of which hampered sentence reading: first, ambiguity concerning word size, since aggregation of the beginning characters of the sentence yielded more than one lexical candidate (e.g., 花 生长 vs. 花生 长), and second, ambiguity concerning grouping direction, since some characters formed a word with either a rightor a left-side neighbor (e.g., the character 长 in 生长 在 and 生 长在).

\section{EXPERIMENT 1}

In Experiment 1, we sought to discriminate between the sequential parsing and the multiple activation hypotheses by asking participants to read sentences that contained a critical four-character sequence. When parsed unidirectionally, from left to right, the character-to-word assignment process always revealed two context-consistent words. For instance, the critical character sequence 专科 学生 can be parsed into 专科 $(\mathrm{C} 12$; college $)$ and 学生 (C34; student) without any parsing ambiguity. Yet, according to the multiple activation hypothesis, ambiguity should be present, because the two center characters of the sequence, 科学 (C23), form a legal word on their own (science).

In the experiment, native speakers of Chinese read sentences with a critical four-character sequence (C1234). In all the conditions, this sequence consisted of two contextconsistent nonoverlapping two-character words, $\mathrm{C} 12$ and C34. In the experimental condition, the two center characters, C23, could also form a word of their own - that is, the grouping of these characters into words was potentially ambiguous. In contrast to this, C23 did not form a word in the control conditions. According to the unidirectional parsing hypothesis, potentially ambiguous and unambiguous critical character sequences should be read with equal ease, since the left-to-right character-to-word parsing will discern a nonoverlapping sequence of two-character words, irrespective of sequence type. That is, $\mathrm{C} 1$ and $\mathrm{C} 2$ should be grouped into one word, and $\mathrm{C} 3$ should be recognized as the first character of a new word that also includes $\mathrm{C} 4$. According to the multiple activation hypothesis, however, reading of an experimental sequence should be more difficult. C2 and $\mathrm{C} 3$ can combine forward (with the following character) to form words C23 and C34, respectively. Moreover, these characters also combine with the preceding character into a legal word, to form $\mathrm{C} 12$ and $\mathrm{C} 23$. This competition of $\mathrm{C} 23$ with $\mathrm{C} 12$ and $\mathrm{C} 34$ for word recognition should be expressed in longer reading durations. ${ }^{3}$

\section{Method}

Participants. Twenty-four students at the State University of New York at Binghamton were paid to participate in the experiment. All the participants either had uncorrected (normal) vision or wore contact lenses, and all were native speakers of Mandarin (PuTongHua) from mainland China.

Materials. All the materials consisted of simplified characters that were ordered from left to right. Fifty-four critical four-character sequences (C1234) were formed, each of which corresponded to a compound word with two nonoverlapping two-character constituent words (C12 and C34-e.g., college student). Thirty-eight of these expressions were compound nouns; the remaining expressions were compound verbs. Critically, each one of these sequences also contained a two-character center sequence (C23) that formed a legal word on its own (see note 3 ). For ease of exposition, these potentially ambiguous $\mathrm{C} 1234$ character sequences will be referred to as experimental, or ambiguous, sequences in the following.

For each one of the 54 ambiguous sequences, two matched control conditions were created: an onset-identical control condition, in which the first two characters $(\mathrm{C} 12)$ corresponded to the first two characters of the ambiguous sequence, and an offset-identical condition in which the last two characters (C34) corresponded to the last two characters of the ambiguous sequence. In the onsetidentical condition, the last two characters were replaced by another context-consistent two-character word ( $\left.\mathrm{C}^{\prime} 4\right)$ whose first character $\left(\mathrm{C}^{\prime}\right)$ did not form a legal word in conjunction with $\mathrm{C} 2$. Analogously, in the offset-identical conditions, the first two characters were replaced with a context-consistent two-character word whose second character (C2') did not form a legal word in conjunction with $\mathrm{C} 3$. Care was taken to match the word frequency and stroke complexity of $\mathrm{C} 12$ and $\mathrm{C} 34$ of ambiguous character sequences with the corresponding word frequencies and stroke complexities of control words (XianDai HanYu PinLu CiDian, 1985). The average word frequencies of $\mathrm{C} 12$ and $\mathrm{C} 12^{\prime}$ were 88.3 and 71.3 per million, and the average numbers of strokes were 14.7 and 15.7; neither difference approached significance $[t(53)=0.778, p>.3$, and $t(53)=0.956$, $p>.3$, respectively]. The average frequencies of C34 and $\mathrm{C}^{\prime} 4$ were 58.58 and 48.72 , and the average numbers of strokes were 15.7 and 16.3 , respectively. Once more, these differences were not reliable $[t(53)=0.742, p>.3$, and $t(53)=0.64, p>.3]$.

All the targets and their control words were embedded in the same sentence shell that contained 20-26 characters, and all the sentences were constructed so that they were legally written with a single punctuation mark, a sentence-final period. Each sentence context had three versions: one containing the experimental fourcharacter sequence $(\mathrm{C} 1234)$, one containing the onset-identical control $\left(\mathrm{C} 12 \mathrm{C}^{\prime} 4\right)$, and one containing the offset-identical control $\left(\mathrm{C} 12^{\prime} \mathrm{C} 34\right)$. All three versions of the critical four-character sequence assumed nearly identical meanings within their sentence context. This was achieved by replacing each experimental C12 and C34 with a meaning-preserving alternative word. The success of this matching procedure was determined in a rating study in which 12 Chinese readers, none of whom participated in the reading experiment, rated the goodness of fit of the center sequence within the sentence shell. A rating of 1 indicated a particularly poor fit, a rating of 7 a particularly good fit. The ratings for the ambiguous, onsetidentical, and offset-identical conditions were 6.03, 5.60, and 5.77, respectively $(p>.10)$.

All the characters of a sentence were ordered from left to right on a line of text, which is standard in modern (simplified) script. The critical character sequence never occupied the beginning or ending location of a sentence. Specifically, 3-12 characters preceded the critical 4-character sequence, and 5-18 characters followed it. An experimental sentence and its two controls are shown in Figure 1. An additional subset of the materials is shown in the Appendix.

Design. Three lists with identical sentence shells were constructed. Eighteen sentences on each list contained a critical character sequence with an ambiguous two-character sequence at the center (C23), and an equal number of sentences contained an onsetidentical and an offset-identical control sequence. A critical letter sequence on one list was replaced with a different critical letter sequence on another, so that the assignment of conditions to a particular sentence shell was counterbalanced across lists. Each participant read only one list of sentences so that there would be no repetition of critical characters.

Apparatus. An NEC 5FGe monitor with 0.28-mm dot pitch was used to display text. All the stimuli were shown in light green on a black background. All the text was shown in $480 \times 640$ VGA mode in a special display routine that used only 111 of the 480 vertical 


\section{Sample Sentences in Experiment 1}

\section{Experimental Sentence:}

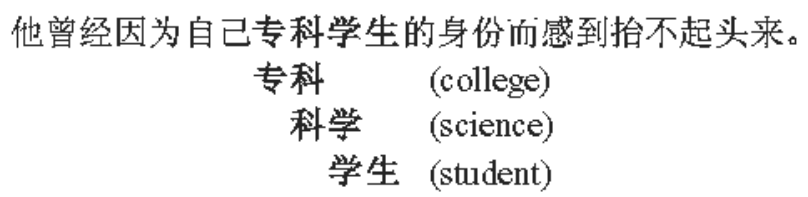

Onset identical:

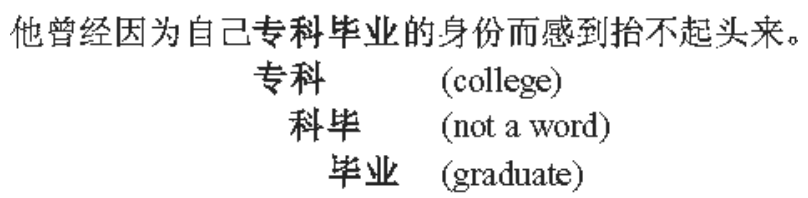

Offset identical: 他曾经因为自己外地学生的身份而感到抬不起头来。 $\begin{array}{cl}\text { 外地 } & \text { (foreign) } \\ \text { 地学 } & \text { (not a word) } \\ \text { 学生 } & \text { (student) }\end{array}$

English translation of the experimental sentence: He used to be embarrassed being just a college student.

Figure 1. An illustration of an ambiguous sentence and its two unambiguous controls in Experiment 1. In this sentence, the $\mathbf{C 2 3}$ pseudoword in the ambiguous condition fits relatively well into sentence context. The critical area and its segmentation are shown in boldface characters. Critical characters were not visually distinct in the experiment.

pixel lines. A Chinese word-processing program, Chinese Star 2.0, was used to generate and display characters, each of which occupied a $24 \times 24$ pixel grid, with strokes occupying a 24 (vertical) $\times 23$ (horizontal) pixel area, so that the width of each character of text was constant. A 1-pixel vertical column separated successive characters. The distance between the reader's eyes and the monitor was set at $65 \mathrm{~cm}$. At this viewing distance, each Chinese character subtended approximately $0.9^{\circ}$ of visual angle.

Eye movements were recorded via a fifth-generation dual-Purkinje SRI eye-tracking system. Viewing was binocular, but eye movements were recorded from the right eye only. The system has a relative visual resolution of $<10 \mathrm{~min}$ of arc, and its output was linear over the vertical and horizontal range of the visual display. Analog input from the eyetracker was digitized via a Data Translation 2801-A A-to-D converter housed in a personal computer. The computer controlled the visual display and stored horizontal and vertical fixation coordinates in 2-msec intervals. These data were used to determine the size of a lateral saccade to the nearest 2-pixel (1/12th of a Chinese character) area and the duration of a fixation to the nearest $2 \mathrm{msec}$.

Procedure. All the participants were tested individually. When a participant arrived in the laboratory, a bite bar was prepared that served to reduce head movements during the experiment. A twodimensional calibration of the eye-tracking system began the experiment. During calibration, the reader was requested to fixate five monitor positions (left top, right top, left bottom, right bottom, and screen center), each consisting of a 12 (vertical) $\times 9$ (horizontal) pixel outline, as they sequentially appeared on the screen. At each fixation location, a sequence of random numbers ranging from 1 to 9 , with a maximal extension of $10 \times 7$ pixels, was shown inside the square, with each digit being visible for between 100 and $400 \mathrm{msec}$.
Occasionally, a smaller $5 \times 4$ pixel target was shown for $400 \mathrm{msec}$ inside the outline, and the participant was requested to respond to the target's onset by pressing the right-side mouse button. The reader's fixation location was sampled for $150 \mathrm{msec}$ after each mouse key activation when a target had been visible. This detection routine was repeated for each of the five monitor positions. The X/Y A-to-D converter values for the five sampled screen fixations were then mapped onto the corresponding CRT locations. After calibration, three lines of five fully illuminated $12 \times 8$ pixel squares were shown, one near each of the four monitor corners and one in the center of the screen. The reader was asked to fixate these locations, and the computed fixation location was echoed back to the screen via a $12 \times 8$ pixel cursor that moved in synchrony with the eyes. The reader was asked to fixate each of the five illuminated locations and was reminded that the task was not to move the cursor onto the illuminated positions but to merely look at each position. The calibration was considered successful when no more than 12 (vertical) and 8 (horizontal) blank pixels intervened between each of the five calibration check positions and the location of the eye-movement-contingent fixation cursor.

After successful calibration, the reader was asked to fixate a $5 \times$ 4 pixel marker at the left side of the screen and to depress a button to display a line of text. Buttonpressing replaced the fixation marker with a sentence and started the recording of eye positions. All the readers were informed that text was written in the standard left-to-right direction as it is used in the writing of simplified Chinese script. After sentence reading was completed, the reader depressed the mouse key, which erased the line of visible text. To encourage sentence comprehension, readers were occasionally asked to repeat a sentence after it had been read. The report was complete and accurate on more than $90 \%$ of the probed trials (see also Inhoff \& Liu, 1997, 1998; Liu, Inhoff, Ye, \& Wu, 2002).

Measurement and Analyses. A character was considered fixated when the line of sight fell on one of its pixels or the blank pixel space preceding it, and two consecutive fixations were considered to be distinct viewing events when they were separated by at least 0.5 of a character space. Otherwise, these fixations were cumulated into a single event. A blink during a fixation was recorded as two consecutive fixations at the same location that were separated by a zero-size saccade. These two fixations were subsequently cumulated into a single fixation duration, which did not include blink duration. Minimum fixation duration was set to $80 \mathrm{msec}$. Shorter durations were excluded, as were outliers of more than $1,500 \mathrm{msec}$. Together with occasional track losses, this resulted in the exclusion of $14 \%$ of the data. We also considered only those instances in which the first fixation on a selected location was preceded by a forward-directed (left-to-right) saccade and in which the critical area was left via another forward-directed saccade, which resulted in the exclusion of $8 \%$ of the trials with counterdirectional saccades. Instances in which readers executed a regression while the critical area was read were included in the analysis, however. Regressions during critical area reading occurred with approximately equal frequency in the ambiguous, the onset-identical, and the offset-identical conditions $(15 \%, 12 \%$, and $13 \%$, respectively).

Eye movements during the reading of two areas were analyzed, one comprising the full critical character sequence ( $\mathrm{C} 1$ to $\mathrm{C} 4)$, and one comprising the two center characters $(\mathrm{C} 23)$ that formed a legal word in the experimental condition, but not in the two control conditions. Gaze duration was used as the primary measure (Inhoff $\&$ Radach, 1998; Inhoff \& Weger, 2003; Rayner, 1998). It consists of the cumulated viewing time on a selected spatial area until the eyes move to a character outside the area. Raw data were averaged to obtain individual condition means that were subjected to inferential statistics. The mean number of raw data that contributed to the computation of a condition mean for $\mathrm{C} 1234$ sequences was 13 ; the highest number was 18 (12 instances) and the lowest number was 1 (1 instance).

Five supplementary measures were also computed. We calculated the size of the saccade to the critical area when it was fixated, the landing location within the critical area in terms of relative character 
Table 1

Eye Movement Measures for the Critical Four-Character Sequence as a Function of Sequence Type in Experiment 1

\begin{tabular}{|c|c|c|c|c|c|c|}
\hline \multirow[b]{3}{*}{ Measure } & \multicolumn{6}{|c|}{ Character-to-Word Assignment } \\
\hline & \multicolumn{2}{|c|}{ Ambiguous } & \multicolumn{2}{|c|}{$\begin{array}{c}\text { Onset } \\
\text { Identical }\end{array}$} & \multicolumn{2}{|c|}{$\begin{array}{c}\text { Offset } \\
\text { Identical }\end{array}$} \\
\hline & $M$ & SEM & $M$ & SEM & $M$ & SEM \\
\hline Skipping rate & 4 & 1.9 & 6 & 2.3 & 4 & 2.0 \\
\hline First-fixation duration & 251 & 13 & 251 & 15 & 258 & 13 \\
\hline Gaze duration & 522 & 36 & 491 & 34 & 502 & 30 \\
\hline Total viewing duration & 690 & 45 & 577 & 36 & 576 & 37 \\
\hline Saccade size & 3.0 & 0.3 & 3.1 & 0.3 & 3.0 & 0.3 \\
\hline Landing position & 1.75 & 0.08 & 1.88 & 0.09 & 1.93 & 0.13 \\
\hline
\end{tabular}

Note-Skipping rate is reported as a percentage value; first-fixation, gaze, and total viewing durations are measured in milliseconds; saccade size is measured in number of characters; and landing position denotes the initially fixated relative character location within a word.

location (1 to 4), the duration of the first fixation on the critical area, and the total time on the area - that is, gaze durations plus the time spent rereading the segment after a location outside the critical area had been fixated. We also examined the relative frequency with which the eyes moved over (skipped) the critical character sequence without fixating it. No eligibility criteria were applied to the skipping data; that is, a critical segment was counted as skipped when the eyes did not land on it, irrespective of the type of eye movement that occurred prior to or after skipping. We used $t$ tests for dependent samples to compare the ambiguous condition with the onset-identical and the offset-identical conditions. The data of all the participants contributed to the critical character sequence data. The data of 1 participant were excluded from the center character (C23) analyses because of lack of data for one of the experimental conditions. In addition to detailed examinations of critical area reading, we also measured the time spent gazing at the segment of the sentence that followed (i.e., was to the right of) the critical character sequence.

\section{Results}

Critical character sequence. The six measures of critical character reading are shown in Table 1. Skipping of the critical four-character area was relatively rare, approximately $3 \%$, and skipping rates did not differ for the three conditions (both $p$ values $>.25$ ). Examination of trials in which the critical area was fixated showed progressively larger effects of critical character sequence type, since a viewing duration measure could include more fixations on the area. Specifically, the duration of the first fixation on the critical sequence was nearly identical in all three conditions (both $p$ values $>.25$ ). Gaze durations showed numerically longer gazes in the ambiguous condition than in the two control conditions. The effect was marginally reliable in the contrast of the ambiguous condition with the onset-identical condition $[t(23)=1.95, p<.06]$, but not in the contrast with the offset-identical condition $[t(23)=1.17, p>.25]$. The effect size further increased when the total viewing duration was measured for which the ambiguity effect was reliable, in comparison with the onset-identical condition $[t(23)=3.86, p<.01]$ and the offset-identical condition $[t(23)=2.21, p<.05]$.

Examination of the two movement-based measures, saccade size and landing position, yielded no reliable effect (all $p$ values $>.25$ ). The mean size of interword sac- cades, slightly less than three character spaces, was almost identical to the mean saccade size in earlier experiments (e.g., Inhoff \& Liu, 1998; Liu et al., 2002; Yang \& McConkie, 1999), indicating that the lexical ambiguity of the character sequence did not influence saccade targeting.

Center character sequence. The six oculomotor measures for center character (C23) reading are shown in Table 2. Mean skipping rate for the $\mathrm{C} 23$ characters was considerably higher than the skipping rate for the full critical character sequence, because the analyzed spatial area was smaller. Skipping rates and first-fixation durations showed numerically small ambiguity effects - more skipping and shorter fixation durations in the two control conditions than in the ambiguous condition - but the effects were not reliable (all $p$ values $>.25$ ). The sequence type effect increased with additional fixations on the $\mathrm{C} 23$ character sequence, and gazes were significantly longer in the ambiguous condition than in the onset-identical condition $[t(22)=2.57]$ or the offset-identical condition $[t(22)=$ 2.59 , both $p \mathrm{~s}<.025]$. Once more, the main effect of sequence type was reliable in the total viewing durations, with longer durations in the ambiguous condition than in the onset-identical condition $[t(22)=2.42, p<.025]$ or the offset-identical condition $[t(22)=2.12, p<.05]$.

The two movement-related measures, saccade size and landing position, showed smaller saccade sizes and smaller position values than did the main analysis, since the eyes could not move as far into a two-character sequence as into a four-character sequence. Critically, neither of the two movement-related measures revealed an effect of sequence type (all $p$ values $>.25$ ), again indicating that the lexical status of the character sequence did not influence saccade targeting.

Post-critical character sequence. Irrespective of the type of critical character sequence, the readers spent approximately $1 \mathrm{sec}$ on the remainder of the sentence, with durations of $1.04,1.03$, and $1.04 \mathrm{sec}$ in the ambiguous, onset-identical, and offset-identical conditions, respectively (both $p$ values $>.25$ ).

Table 2

Eye Movement Measures for the Center Two-Character Sequence as a Function of Sequence Type in Experiment 1

\begin{tabular}{|c|c|c|c|c|c|c|}
\hline \multirow[b]{3}{*}{ Measure } & \multicolumn{6}{|c|}{ Character-to-Word Assignment } \\
\hline & \multicolumn{2}{|c|}{ Ambiguous } & \multicolumn{2}{|c|}{$\begin{array}{c}\text { Onset } \\
\text { Identical }\end{array}$} & \multicolumn{2}{|c|}{$\begin{array}{c}\text { Offset } \\
\text { Identical }\end{array}$} \\
\hline & $M$ & SEM & $M$ & $S E M$ & $M$ & SEM \\
\hline Skipping rate & 14 & 3.1 & 17 & 2.6 & 16 & 3.5 \\
\hline First-fixation duration & 298 & 12 & 273 & 8 & 282 & 13 \\
\hline Gaze duration & 353 & 20 & 306 & 17 & 317 & 14 \\
\hline Total viewing duration & 380 & 20 & 340 & 18 & 342 & 18 \\
\hline Saccade size & 2.7 & 0.4 & 2.3 & 0.09 & 2.2 & 0.1 \\
\hline Landing position & 1.4 & 0.04 & 1.4 & 0.04 & 1.4 & 0.04 \\
\hline
\end{tabular}

Note-Skipping rate is reported as a percentage value; first-fixation, gaze, and total viewing durations are measured in milliseconds; saccade size is measured in number of characters; and landing position denotes the initially fixated relative character location within a word. 


\section{Discussion}

The readers spent significantly more time on the critical character sequence when its two center characters could be a member of more than one word than when each character could be assigned to only one legal word. This occurred even though a strictly left-to-right parsing of characters into words should have assigned each character to just one word in all the conditions.

In defense of a strictly serial left-to-right parse, it could be argued that readers spent more time viewing an ambiguous C1234 character sequence than a control sequence because its left-to-right parsing was more difficult and more error prone. To examine this alternative, we asked 8 native speakers of Chinese, who had not participated in the sentence-reading study, to determine word boundaries for the critical C1234 sequence in the ambiguous condition and for those in the corresponding control conditions. Specifically, each participant was initially shown all sentence fragments up to $\mathrm{C} 1$ and then was asked whether $\mathrm{C} 1$ was followed by a word boundary. After this, the sentence fragment was presented up to $\mathrm{C} 2$, and another sentence boundary decision was to be made. In two additional cycles, the participants were asked to determine word boundaries when the sentence fragment was shown up to $\mathrm{C} 3$ and then up to $\mathrm{C} 4$.

The word boundary decisions were clear-cut in that they revealed virtually identical left-to-right character-toword assignments in the three conditions. Specifically, the decisions that there was a word boundary after characters C1 to C4 were $13 \%, 99 \%, 11 \%$, and $99 \%$, respectively, for the ambiguous condition; $13 \%, 99 \%, 10 \%$, and $99 \%$ for the onset-identical condition; and 10\%, 97\%, 11\%, and $98 \%$ for the offset-identical condition.

The presence of a robust spatial word ambiguity effect under these conditions implies that the lexical form of C23 must have been active during critical area viewing (see note 3). As such, the ambiguity effect is consistent with the multiple activation hypothesis. According to this view, left-to-right-directed character pairings (e.g., the pairing of $\mathrm{C} 1$ with $\mathrm{C} 2$ and of $\mathrm{C} 3$ with $\mathrm{C} 4$ ) can co-occur with counterdirectional pairings (e.g., of C3 with $\mathrm{C} 2$ ). More than one lexical candidate will thus compete for the two center characters in the ambiguous condition, but not in the two control conditions. The cost of C23 ambiguity took time to emerge. It was negligible in the first-fixation durations and increased as more fixations on the critical area or the $\mathrm{C} 23$ sequence were included in the processing measure. This particular time course suggests that deleterious effects of character-to-word ambiguity could have occurred relatively late during critical area viewing.

The time course of the ambiguity effect could be distorted, however. Although ambiguous and control sequences were well matched, it is possible that the two types of character sequences differed on relevant item dimensions. Since the two center characters of the ambiguous condition formed a word on their own, they could have been somewhat more common and more familiar than the corresponding control characters. Counts of individual character frequencies reveal such a tendency, although it was relatively moderate.
Specifically, the frequencies of occurrence for the two ambiguous C2 and C3 characters were 314.11 and 444.72 per million, respectively. The frequencies of the corresponding control characters were 230.94 and 415.56 per million. The somewhat higher familiarity of the ambiguous character forms could have facilitated their recognition, thereby opposing costs incurred by the competition of coactive lexical candidates. The net effect could have been a relatively small and unreliable difference between the ambiguous condition and the two control conditions when first-fixation durations were measured. In Experiment 2, we examined whether properties of C23 in Experiment 1 distorted the time course of the ambiguity effect.

\section{EXPERIMENT 2}

To eliminate confounding effects of uncontrolled item properties, Experiment 2 used a within-item design so that the identical C23 character sequence was either ambiguous or not. A subset of the experimental sentences of Experiment 1 was used that contained a lexically ambiguous $\mathrm{C} 23$ sequence in the center of the critical character sequence. For these sentences, a matched set of control sentences was constructed. These controls contained the same C23 sequence as their experimental matches, but $\mathrm{C} 23$ now formed a consistent word on its own. C1 and C4 of these control sequences either were words of their own or formed a word with another adjacent neighbor ( $\mathrm{C} 01$ and $\mathrm{C} 45$ ). The time spent viewing the identical character sequence (C23) could thus be examined as a function of its ambiguity.

To further chart the time course of the ambiguity effect, Experiment 2 repeated characters C23 later in the sentence. Repetition followed either a relatively short lag, so that the first and the second occurrences of $\mathrm{C} 23$ were separated by five or fewer characters, or a long lag, so that the two occurrences were separated by five or more characters. In all cases, C23 formed a legal word on its second occurrence.

If resolution of the ambiguity of a character sequence was context dependent and time consuming, lexical ambiguity of $\mathrm{C} 23$ could influence subsequent $\mathrm{C} 23$ reading, so that a second $\mathrm{C} 23$ reading could be more effective when the initially encountered C23 formed a word than when it did not. Moreover, this benefit could be larger in the shortlag condition than in the long-lag condition. Somewhat analogous studies with English text provide some support for this contention. Binder and Morris (1995) used sentences with two occurrences of a lexically ambiguous homograph for which context required instantiation of either the same meaning or different word meanings. Under these conditions, readers spent less time viewing the second occurrence of the homograph when the previously used word meaning was to be accessed.

\section{Method}

Participants. Twenty students at the State University of New York at Binghamton were paid to participate in Experiment 2. Approximately half of them had participated in Experiment 1, which 
had been conduced two semesters (1 year) earlier. All the participants either had uncorrected (normal) vision or wore contact lenses and were native speakers of Mandarin (PuTongHua) from mainland China.

Materials and Design. Thirty-two ambiguous four-character sequences from Experiment 1 were used in Experiment 2. C12 and C34 formed context-consistent words; the two center characters of these sequences (C23) also formed a legal word. Thirty-two matched unambiguous four-character sequences were constructed that contained the identical $\mathrm{C} 23$ sequence. In these sentences, $\mathrm{C} 23$ formed a context-consistent word, and neither $\mathrm{C} 2$ nor $\mathrm{C} 3$ formed a word in combination with another adjoining character. $\mathrm{C} 1$ and $\mathrm{C} 4$ of these sequences either formed words of their own or formed a word in combination with another spatial neighbor. Sentence pairs in the two conditions were closely matched. In particular, the character sequences preceding the critical character sequence were nearly identical in the two conditions. An experimental sentence and its control are shown in Figure 2. A representative subset of five other sentence pairs is shown in the Appendix.

C23 was repeated in the experimental and control sentences, now always forming a context-consistent word. The distance between the first and the second occurrences of $\mathrm{C} 23$ was controlled. In half of the sentences, five or fewer characters intervened between the repeated C23 sequence; on the remaining trials, more than five characters intervened between the repeated character sequence. To mask the presence of a character sequence's repetition, the stimulus materials also included 32 filler sentences that did not contain a repeated two-character sequence.

Two lists of matched sentences were used. Each list contained 64 sentences, 16 in which C23 was ambiguous and 16 in which it was unambiguous. The remaining sentences were fillers. Sentences with an ambiguous $\mathrm{C} 23$ sequence on one list contained an unambiguous control sentence on the other list, and vice versa. Each participant read only one list. As in Experiment 1, the viewings of C1234 and of $\mathrm{C} 23$ were analyzed separately. Paired comparisons for dependent samples were used to determine the effect of lexical ambiguity in these sets of data. The time spent reading the second occurrence of

\section{Sample Sentences in Experiment 2}

Ambiguous Condition:

她曾试图通过感化学生来激起学生对化学的兴趣。
感化 $\quad$ (astronony)
化学 $\quad$ (chemistry)
学生 (student)

English Translation:

By talking inspiringly to students, she tried

to motivate them to be interested in chemistry.

\section{Control Condition:}

她试图通过演示化学现象来激起学生对化学的兴趣。

English Translation:

By demonstrating chemistry phenomena, she tried to motivate them to be interested in chemistry.

Figure 2. An ambiguous sentence and its control in Experiment 2 . In this ambiguous sentence, $\mathbf{C 2 3}$ fits relatively poorly into prior sentence context.
C23 was analyzed as a function of the lexical status of the initially encountered C23 sequence (ambiguous vs. unambiguous) and distance ( $\leq 5$ vs. $>5$ characters).

\section{Results}

Critical four-character sequence. The six measures of critical area reading are shown as a function of sequence type in Table 3 . Skipping rates were again relatively low $(3 \%)$ and of similar magnitude in the ambiguous and unambiguous conditions. The viewing duration measures from trials in which the critical sequence was fixated at least once revealed robust effects of character-to-word parsing ambiguity. Specifically, first-fixation durations were 30 msec longer $[t(19)=2.26, p<.05]$ when the character-to-word assignment of center characters was ambiguous than when it was unambiguous. The effect increased in size as more fixations were included, gazes being 69 msec longer $[t(19)=2.99, p<.01]$ and total viewing duration being $132 \mathrm{msec}$ longer $[t(19)=3.92$, $p<.01]$ in the ambiguous condition. Again, ambiguity influenced neither saccade size $[t(19)=1.60, p>.16]$ nor landing position $[t(19)=0.47, p>.6]$.

Center character $(\mathbf{C 2 3})$ reading. The different oculomotor measures of center character reading are also shown in Table 3. Skipping of C23 occurred somewhat less often $(13 \%)$ when it was ambiguous than when it was unambiguous (18\%). The effect did not reach statistical significance, however $[t(19)=1.65, p>.1]$. The effect pattern for the three viewing duration measures is virtually identical to the effect pattern of the full critical character sequence, with robust costs of ambiguity for first-fixation duration $[t(19)=2.19, p<.05]$, gaze duration $[t(19)=$ $3.05, p<.01]$, and total viewing duration $[t(19)=4.05$, $p<.01]$. Again, character ambiguity did not influence saccade size and landing position $[t=0.25$ and $t(19)=$ $1.36, p>.1$, respectively].

Eye movement measures for the second reading of $\mathrm{C} 23$ are shown in Table 4. None of the measures revealed a reliable effect, except for an unexpected interaction of initial sequence ambiguity and repetition distance in the saccade data $[F(1,19)=4.54, p<.05]$. The source of this interaction is unclear. Total viewing duration also revealed a numeric effect $(28 \mathrm{msec}$ ) of initial character ambiguity in the immediate condition, but not in the delayed condition. The corresponding statistical interaction of prior ambiguity and repetition distance did not approach significance, however $[F(1,19)=1.29, p>.28]$.

\section{Discussion}

Skilled readers of Chinese spent more time viewing the identical sequence of characters when the C23 constituents could be assigned to more than one word than when they could be assigned to one word only. The ambiguity effect emerged at an earlier point in time than in Experiment 1 , now being present in all viewing duration measures, including the first-fixation duration. Presumably, this occurred because of better controlled item properties in the present experiment. 
Table 3

Eye Movement Measures for the Reading of the Critical Four-Character Sequence and the Central Two-Character Sequence as a Function of Sequence Type in Experiment 2

\begin{tabular}{|c|c|c|c|c|c|c|c|c|}
\hline \multirow[b]{4}{*}{ Measure } & \multicolumn{8}{|c|}{ Character-to-Word Assignment } \\
\hline & \multicolumn{4}{|c|}{ Four-Character Sequence } & \multicolumn{4}{|c|}{ Center Characters } \\
\hline & \multicolumn{2}{|c|}{ Ambiguous } & \multicolumn{2}{|c|}{ Control } & \multicolumn{2}{|c|}{ Ambiguous } & \multicolumn{2}{|c|}{ Control } \\
\hline & $M$ & $S E M$ & $M$ & $S E M$ & $M$ & SEM & $M$ & SEM \\
\hline Skipping rate & 3 & 0.02 & 3 & 0.03 & 13 & 0.03 & 18 & 0.02 \\
\hline First-fixation duration & 263 & 15 & 233 & 10 & 276 & 13 & 250 & 10 \\
\hline Gaze duration & 493 & 15 & 424 & 28 & 335 & 14 & 291 & 9 \\
\hline Total viewing duration & 635 & 49 & 504 & 30 & 422 & 26 & 315 & 11 \\
\hline Saccade size & 3.0 & 0.14 & 2.8 & 0.16 & 2.7 & 0.14 & 2.7 & 0.12 \\
\hline Landing position & 2.0 & 0.09 & 2.0 & 0.07 & 1.4 & 0.03 & 1.5 & 0.03 \\
\hline
\end{tabular}

Note-Skipping rate is reported as a percentage value; first-fixation, gaze, and total viewing durations are measured in milliseconds; saccade size is measured in number of characters; and landing position denotes the initially fixated relative character location within a word.

These results suggest that the grouping of characters into words occurred relatively early during the viewing of the critical character sequence, perhaps involving the competition of coactive word forms for character constituents. As in Experiment 1, the effect of ambiguity increased when more fixations on the critical area could be taken into account. Once more, ambiguity was resolved by the time the eyes moved onto the sentence segment that followed the critical segment.

\section{GENERAL DISCUSSION}

The main goal of the present study was to determine how a sequence of Chinese characters is segmented into words in the absence of distinct visual segmentation cues. Two word-finding strategies were contrasted: the unidirectional parsing hypothesis, according to which a leftto-right-progressing parse determines word boundaries, and the multiple activation hypothesis, according to which adjacent characters merge into word units irrespective of the spatial direction of the grouping. In harmony with the multiple activation assumption, readers spent more time on a critical character sequence when some of its constituent characters formed a word with either a right- or a left- side character. This occurred even though the left-to-right character grouping unambiguously assigned constituent characters to context-consistent words. The costs of the grouping ambiguity were immediate in Experiment 2, in that it influenced the duration of the first fixation on the character sequence, and were sustained, in that costs increased as additional fixations of the critical area were included in the processing measure. A similar effect pattern emerged in the gaze and total viewing durations in Experiment 1, although the effect sizes were numerically smaller than those in Experiment 1. Moreover, the ambiguity effect was negligible in the first-fixation duration data. Presumably, this occurred because the slightly higher frequency of ambiguous characters in Experiment 1 obscured the immediate expression of ambiguityrelated processing costs. In all cases, the lexical status of C23 was resolved while the critical area was viewed, since there were no effects of $\mathrm{C} 23$ ambiguity during the reading of subsequent text.

In defense of the unidirectional left-to-right parsing hypothesis, it could be argued that a recursive parsing algorithm, similar to that proposed by Libben (1994), can account for the effects in Experiments 1 and 2, if each character of Chinese text was the starting point of

Table 4

Eye Movement Measures for the Reading of the Repeated TwoCharacter Sequence as a Function of Prior Sequence Type and the Proximity of the Initial Encounter in Experiment 2

\begin{tabular}{|c|c|c|c|c|c|c|c|c|}
\hline \multirow[b]{4}{*}{ Measure } & \multicolumn{8}{|c|}{ Character-to-Word Assignment } \\
\hline & \multicolumn{4}{|c|}{ Initial Ambiguous } & \multicolumn{4}{|c|}{ Initial Unambiguous } \\
\hline & \multicolumn{2}{|c|}{ Near } & \multicolumn{2}{|c|}{ Far } & \multicolumn{2}{|c|}{ Near } & \multicolumn{2}{|c|}{ Far } \\
\hline & $M$ & $S E M$ & $M$ & $\overline{S E M}$ & $M$ & $S E M$ & $M$ & $S E M$ \\
\hline First-fixation duration & 245 & 17 & 278 & 17 & 244 & 14 & 244 & 12 \\
\hline Gaze duration & 339 & 25 & 326 & 17 & 328 & 16 & 336 & 16 \\
\hline Total viewing duration & 383 & 25 & 344 & 20 & 355 & 22 & 354 & 16 \\
\hline Saccade size & 2.1 & 0.16 & 2.5 & 0.23 & 2.6 & 0.20 & 2.3 & 0.16 \\
\hline Landing position & 1.3 & 0.06 & 1.3 & 0.06 & 1.4 & 0.06 & 1.3 & 0.04 \\
\hline
\end{tabular}


a new parse. After the parsing of $\mathrm{C} 1$ to $\mathrm{C} 4$ of the critical sequence, ${ }^{4}$ a reader would thus parse $\mathrm{C} 2$ to $\mathrm{C} 5$, then $\mathrm{C} 3$ to $\mathrm{C} 6$, and so forth. In this scheme, the sequential $\mathrm{C} 2$ to $\mathrm{C} 5$ parsing would reveal the lexical status of $\mathrm{C} 23$, which could interfere with the prior parsing of characters $\mathrm{C} 12$ and $\mathrm{C} 34$ into words.

Strictly serial left-to-right parsing of letters in words may be feasible when English text is read. Most words in this language are short and contain a single root morpheme. The typical parse will thus involve a single leftto-right conjoining of letters into words prior to lexical access, according to this model. After this, letter-to-word parsing can be applied to the next spatial unit; that is, there is no overlap in the parsing of successive words in the text. The onset and offset points of each parse are well defined by interword blanks and, thus, impose few, if any, demands on memory.

The strictly serial recursive parsing of Chinese text, with each character serving as the starting point of a new parse, would be substantially more laborious and memory demanding, however. Many Chinese characters can be words on their own; hence, recursive parsing of a character sequence would be the rule, rather than the exception. Moreover, if each character could be the starting point of a new parse, the spatial areas of successive parses would have substantial overlap, and readers would need to remember the onset and offset locations of each parse, since the corresponding onset and offset characters are not visually distinct.

The typical eye movement pattern during sentence reading also argues against the recursive unidirectional parsing of Chinese characters to words during reading. If each character could serve as the starting point of a new parse, regressions - to the location of the onset of a new recursive parse - should be relatively common. Regression rates for Chinese text should thus be considerably higher than regression rates for alphabetic text. Although comparisons across scripts and text types must be considered with caution, the regression rate for Chinese text does not appear to be inflated. Regression rates for English range between $5 \%$ and $25 \%$, depending on text difficulty (Rayner, 1998). Regression rate was $14 \%$ in the present study and slightly higher (18.4\%) in Yang and McConkie's (1999) study, both of which involved the reading of unrelated sentences. Regression rate was substantially lower (4\%) when relatively simple text consisting of excerpts from popular Chinese news magazines was read (Inhoff, Liu, \& Tang, 1999).

Rather than determining word units — or word boundaries - via a unidirectional parse, readers of Chinese appear to find word units by grouping spatially adjacent characters without directional constraints. A character can thus combine with a neighboring character to form a word, irrespective of whether the character is to its left or its right. This was the case in the ambiguous condition in Experiments 1 and 2, where $\mathrm{C} 3$ combined with a character to its left (C2), even though C12 formed a context-consistent word. Despite the hypothesized lack of directional constraint, grouping of spatially adjacent characters into po- tential words may be an effective means of finding word boundaries, because relatively few character-to-word groupings are possible at any point in time and because other available constraints favor some groupings over others.

The spatial range from which readers of Chinese text obtain useful information during each fixation is limited, encompassing approximately five characters, not all of which are fully identified (Inhoff \& Liu, 1997, 1998; Liu et al., 2002). Knowledge that the length of a word cannot exceed four characters and that the majority of words contain two characters can provide a useful grouping heuristic for the characters within the perceptual span. When, for instance, the identity of four characters can be determined, only 3 two-character groupings are possible $(\mathrm{C} 12$, $\mathrm{C} 23$, and C34).

One early source of constraint that could be applied to these groupings is the likelihood, or frequency, of a particular character-to-word grouping. One-character words could be discerned by virtue of the rarity with which they co-occur with their immediate spatial neighbors. Conversely, characters that form common two-character words could stand out because they typically occur together. To explore this possibility, we applied a supplementary analysis to the data from Experiment 2 that took the word frequency of $\mathrm{C} 23$ into account, our working assumption being that a relatively high $\mathrm{C} 23$ frequency should benefit critical area processing when $\mathrm{C} 23$ is in fact a word, as occurred in the control condition, but not when these characters are constituents of different words, as occurred in the ambiguous condition.

Frequency counts for the $\mathrm{C} 23$ character sequence were determined. A median split was applied to the $\mathrm{C} 23$ frequencies in the ambiguous and control conditions to create two equal-sized groups, one with a relatively high frequency of occurrence (a mean word frequency of 385 per million) and one with a medium frequency of occurrence (114 per million). Although this frequency contrast was quite weak, in that the frequency of occurrence exceeded 100 per million for both groups of words, it did show the expected pattern of gaze durations for critical area reading. Specifically, gaze duration for a critical character sequence with a high-frequency C23 was $405 \mathrm{msec}$ in the control condition and $490 \mathrm{msec}$ in the ambiguous condition, yielding an 85 -msec effect of ambiguity. The corresponding gaze durations for a critical character sequence with a low-frequency C23 were 439 and $494 \mathrm{msec}$, respectively, thus yielding a $30-\mathrm{msec}$ smaller effect of ambiguity. The interaction of word frequency and ambiguity was not reliable, however $(p>.25)$, perhaps because of the relatively low power of our post hoc comparison. Although the precise role of co-occurrence frequency remains to be established, the presence of a moderate (34-msec) effect of word frequency in the control condition $[t(19)=$ $1.95, p<.07]$, together with a negligible frequency effect for the identical character sequence in the ambiguous condition ( $4 \mathrm{msec})$, is consistent with the notion of a frequency-based $\mathrm{C} 23$ grouping that must be overcome in the ambiguous condition. 
Another constraint that may be used to select a particular character grouping could be the success with which all the identified characters within the perceptual span - and all prior characters - can be grouped into spatially nonoverlapping words. The grouping of $\mathrm{C} 23$ into a word in the ambiguous conditions in Experiments 1 and 2 orphans $\mathrm{C} 1$ and $\mathrm{C} 4$. The alternative grouping, $\mathrm{C} 12$ and $\mathrm{C} 34$, is more successful in that it does not create stand-alones. In the present study, the competition of word forms for a constituent character could be resolved when characters other than $\mathrm{C} 2$ and $\mathrm{C} 3$ are taken into account.

The results of Experiment 2 also show that the resolution of a character-to-word grouping ambiguity in Chinese differs from the resolution of lexical ambiguity during the reading of English. Assignment of characters C23 to two different words in the ambiguous condition in Experiment 2 did not have an influence on their reading when they subsequently formed a single word. The assignment of a particular meaning to a homograph in English, by contrast, impedes the assignment of a different meaning to it when that is subsequently required (Binder \& Morris, 1995). One possible account for this discrepancy is that there may be no surviving orthographic or lexical representation of an incorrectly grouped ambiguous $\mathrm{C} 23$ character sequence. That is, once these characters are grouped as $\mathrm{C} 12$ and $\mathrm{C} 34$, their orthographic and lexical representation may no longer impede the assignment of meaning to a subsequently encountered lexical form of $\mathrm{C} 23$.

Unique properties of Chinese script, such as the use of morpho-syllabic characters and the lack of interword spacing, could require the development of script-specific skills for the finding of word boundaries. Nevertheless, the present data have implications for the understanding of lexical processing in other scripts as well. Specifically, our data show that spatially overlapping word forms can be coactive during a fixation. As such, they are consistent with studies with English text according to which the orthographic and lexical processing of spatially adjacent words can overlap in time (e.g., Inhoff, Starr, \& Shindler, 2000). Temporal overlap in the linguistic processing of successive morphemes and words may thus occur when these units are relatively short, irrespective of script type.

\section{REFERENCES}

Binder, K. S., \& Morris, R. (1995). Eye movements and lexical ambiguity resolution: Effects of prior encounter and discourse topic. Journal of Experimental Psychology: Learning, Memory, \& Cognition, 21, 1186-1196.

CHen, J.-Y. (1999). Word recognition during the reading of Chinese sentences: Evidence from studying the word superiority effect. In J. Wang, A. W. Inhoff, \& H.-C. Chen (Eds.), Reading Chinese script: A cognitive analysis (pp. 239-256). Mahwah, NJ: Erlbaum.

Epelboim, J., Booth, J. R., \& Steinman, R. M. (1994). Reading unspaced text: Implications for theories of reading eye movements. $\mathrm{Vi}$ sion Research, 34, 1735-1766.

FisheR, D. F. (1976). Spatial factors in reading and search: The case for space. In R. A. Monty \& J. W. Senders (Eds.), Eye movements and psychological processes (pp. 417-427). Hillsdale, NJ: Erlbaum.

Hsu, S.-H., \& HuANG, K.-C. (2000a). Effects of word spacing on reading Chinese text from a video display terminal. Perceptual \& Motor Skills, 90, 81-92.
Hsu, S.-H., \& Huang, K.-C. (2000b). Interword spacing in Chinese text layout. Perceptual \& Motor Skills, 91, 355-365.

INHOFF, A. W., \& LIU, W. (1997). The perceptual span during the reading of Chinese text. In H. C. Chen (Ed.), Cognitive processing of Chinese and related Asian languages (pp. 243-266). Hong Kong: Chinese University of Hong Kong Press.

InHoFF, A. W., \& LIU, W. (1998). The perceptual span and oculomotor activity during the reading of Chinese sentences. Journal of Experimental Psychology: Human Perception \& Performance, 24, 20-34.

INHOFF, A. W., LiU, W., \& TANG, H. (1999). Use of prelexical and lexical information during Chinese sentence reading: Evidence from eyemovement studies. In J. Wang, A. W. Inhoff, \& H. C. Chen (Eds.), Reading Chinese script: A cognitive analysis (pp. 223-239). Mahwah, NJ: Erlbaum.

InhoFf, A. W., LiU, W., WANG, J., \& Fu, D. J. (1997). Use of spatial information during the reading of Chinese text. In D. L. Peng, H. Shu, \& H. C. Chen (Eds.), Cognitive research on Chinese language (pp. 296329). Beijing: Shan Dong Educational Publishing.

INHOFF, A. W., \& RADACH, R. (1998). Definition and computation of oculomotor measures in the study of cognitive processes. In G. Underwood (Ed.), Eye guidance in reading and scene perception (pp. 2954). Amsterdam: Elsevier.

INHOFF, A. W., \& RADACH, R. (2002). The biology of reading: The use of spatial information in the reading of complex words. Comments on Modern Biology: Pt. C. Comments on Theoretical Biology, 7, 121138.

Inhoff, A. W., Radach, R., Eiter, B. M., \& Skelly, M. (2003). Exterior letters are not privileged in the early stage of visual word recognition during reading. Journal of Experimental Psychology: Learning, Memory, \& Cognition, 29, 894-900.

InHoff, A. W., RaDACH, R., \& Heller, D. (2000). Complex compounds in German: Interword spaces facilitate segmentation but hinder assignment of meaning. Journal of Memory \& Language, 42, 23-50.

InHOFF, A. W., StaRR, M., \& SHINDLER, K. L. (2000). Is the processing of words during eye fixations in reading strictly serial? Perception \& Psychophysics, 62, 1474-1484.

INHOFF, A. W., \& WEGER, U. (2003). Advancing the methodological middle ground. In J. Hyönä, R. Radach, \& H. Deubel (Eds.), The mind's eye: Cognitive and applied aspects of eye movements (pp. 335344). Amsterdam: Elsevier.

Juhasz, B. J., INHOFF, A. W., \& RAYNER, K. (2005). The role of spatial layout in compound words. Language \& Cognitive Processes, 20, 291-316.

KaJiI, N., NAZIR, T., \& OsaKa, N. (2001). Eye movement control in reading unspaced text: The case of Japanese script. Vision Research, 41, 2503-2510.

Libben, G. (1994). How is morphological decomposition achieved? Language \& Cognitive Processes, 9, 369-391.

LiU, W., INhoff, A. W., Ye, Y., \& WU, C. (2002). Use of parafoveally visible characters during the reading of Chinese sentences. Journal of Experimental Psychology: Human Perception \& Performance, 28, 1213-1227.

Malt, B. C., \& Seamon, J. G. (1978). Peripheral and cognitive components of eye guidance in filled-space reading. Perception \& Psychophysics, 23, 399-402.

McConkie, G. W., Kerr, P. W., Reddix, M. D., \& Zola, D. (1988). Eye movement control during reading: I. The location of initial eye fixations on words. Vision Research, 28, 1107-1118.

Morris, R. K., Rayner, K., \& Pollatsek, A. (1989). Eye movement guidance in reading: The role of parafoveal letter and space information. Journal of Experimental Psychology: Human Perception \& Performance, 16, 268-281.

O'Regan, J. K., \& JaCOBS, A. M. (1992). Optimal viewing position effect in word recognition: A challenge to current theory. Journal of Experimental Psychology: Human Perception \& Performance, 18, 185-197.

Pollatsek, A., \& Rayner, K. (1982). Eye movement control in reading: The role of word boundaries. Journal of Experimental Psychology: Human Perception \& Performance, 8, 817-833.

RADACH, R., \& McConKIE, G. W. (1998). Determinants of fixation positions in words during reading. In G. Underwood (Ed.), Eye guidance in reading and scene perception (pp. 77-100). Amsterdam: Elsevier. 
RAYNER, K. (1979). Eye guidance in reading: Fixation locations within words. Perception, 8, 21-30.

RAYNER, K. (1998). Eye movements in reading and information processing: 20 years of research. Psychological Bulletin, 124, 372-422.

Rayner, K., Fischer, M. H., \& Pollatsek, A. (1998). Unspaced text interferes with both word identification and eye movement control. Vision Research, 38, 1129-1144.

Reichle, E. D., Pollatsek, A., Fisher, D. L., \& Rayner, K. (1998). Toward a model of eye movement control in reading. Psychological Review, 105, 125-157.

Reichle, E. D., Rayner, K., \& Pollatsek, A. (2003). The E-Z Reader model of eye-movement control in reading: Comparisons to other models. Behavioral \& Brain Sciences, 26, 445-476.

Tsai, J. L., \& McConkie, G. W. (2003). Where do Chinese readers send their eyes? In J. Hyönä, R. Radach, \& H. Deubel (Eds.), The mind's eye: Cognitive and applied aspects of eye movement research (pp. 159-176). Amsterdam: Elsevier.

Xiandai HanYou PinLu CiDian [Modern Chinese Frequency Dictionary] (1985). Beijing: Beijing Language Institute Press.

YAng, H. M., \& McConkie, G. W. (1999). Reading Chinese: Some basic eye-movement characteristics. In J. Wang, A. W. Inhoff, \& H. C. Chen (Eds.), Reading Chinese script: A cognitive analysis (pp. 207222). Mahwah, NJ: Erlbaum.

Yu, B., Zhang, W., Jing, Q., Peng, R., Zhang, G., \& Simon, H. A. (1985). STM capacity for Chinese and English language materials. Memory \& Cognition, 13, 202-207.

\section{NOTES}

1. The removal of interword spaces can also be informative under some circumstances - for example, when it signals the unification of constituent word meanings. In Inhoff, Radach, and Heller (2000), the duration of the final fixation(s) on morphologically complex words tended to be shorter when they were spatially unified. In the context of other interword spaces, spatial unification defined the sequence of words for which a unifying meaning was to be determined. With compound words, spatial unification also defined the location of the last constituent word, the lexical head, that determined a compound's class membership.

2. Our (Inhoff et al., 1997) study contained three word segmentation conditions: a standard condition with equidistant spacing between characters, a word condition with increased spaces between words, and a random space condition with increased spaces being randomly inserted between characters. Under these conditions, sentence reading times and fixation durations were virtually identical in all three conditions.

3 . We cannot determine the precise nature of the ambiguity effect. It could be due to a conflict in the character-to-word assignment in the ambiguous condition or to the contextual incongruence of an incorrectly recognized C23 in the ambiguous condition. However, irrespective of the precise nature of the ambiguity effect, its presence implies that characterto-word parsing was not strictly serial.

4. If $\mathrm{C} 1$ is a word, recursion will take a second pass to determine whether $\mathrm{C} 12$ is a word as well, because, if it is, this could be followed by yet another recursive pass. 


\section{Examples From Experiment 1}

Ambiguous Translation

Control 1 (onset identical)

Translation

Control 2 (offset identical) Translation

Ambiguous Translation

Control 1 (onset identical) Translation

Control 2 (offset identical) Translation

Ambiguous Translation

Control 1 (onset identical)

Translation

Control 2 (offset identical) Translation

Ambiguous Translation

Control 1 (onset identical) Translation

Control 2 (offset identical) Translation

Ambiguous Translation

Control 1 (onset identical) Translation

Control 2 (offset identical) Translation

Ambiguous
Translation
Control
Translation
Ambiguous
Translation
Control
Translation
Ambiguous
Translation
Control
Translation
Ambiguous
Translation
Control
Translation
Ambiguous
Translation
Control
Translation

有关部门再三强调市售保安装置必须得到公安部门的批准和认可。

It was emphasized that the security device must be approved by the police department. 有关部门再三强调市售保安器材必须得到公安部门的批准和认可。

It was emphasized that the security equipment must be approved by the police department. 有关部门再三强调市售防盗装置必须得到公安部门的批准和认可。

It was emphasized that the theftproof device must be approved by the police department. 令人感兴趣的是为什么移动物体在相同的背景下更容易被觉察。

It is interesting that moving objects are easier to be detected at the same background. 令人感兴趣的是为什么移动对象在相同的背景下更容易被觉察。

It is interesting that moving things are easier to be detected at the same background. 令人感兴趣的是为什么闪伢物体在相同的背景下更容易被觉察。

It is interesting that flickering objects are easier to be detected at the same background. 他曾经因为自己专科学生的身份而感到抬不起头来。

He used to be ashamed about his college student status. 他曾经因为自己专科毕业的身份而感到抬不起头来。 He used to be ashamed about his college diploma status. 他曾经因为自己外地学生的身份而感到抬不起头来。

He used to be ashamed about his foreign student status. 小猴为获取食物而采用的灵活动作真是令人不可思议。

It is amazing that the little monkey used such agile action to get the food. 小猴为获取食物而采用的灵活技巧真是令人不可思议。

It is amazing that the little monkey used such agile skill to get the food. 小猴为获取食物而采用的轻快动作真是令人不可思议。

It is amazing that the little monkey used such quick action to get the food. 对方的诚意已经从他同意见面的允诺中得到体现。

Their agreement to meet represented their sincerity. 对方的诚意已经从他同意访问的允诺中得到体现。 Their agreement to visit represented their sincerity. 对方的诚意已经从他安排见面的允诺中得到体现。 Their arrangement to meet represented their sincerity.

\section{Examples From Experiment 2}

有效的施工程序使这个工程的进度非常迅速

Because of the valid working procedure, this project proceeded very quickly. 有效的工程安排使这个工程的进度非常迅速

Because of the valid project arrangement, this project proceeded very quickly. 教练强调掌握举重要领是成功的重要先决条件

The coach stressed that mastering the elements of weight lifting was important for success. 教练强调第一重要的是灵活性第二重要的才是耐力

The coach stressed the primary importance of flexibility and the secondary importance of patience. 这篇出色的会议论文让教授们议论了好几天

This excellent conference paper was discussed by the professors for several days. 这段出色的总结议论让教授们议论了好几天

This excellent general discussion was talked about by the professors for several days. 他最终点头同意见面其实已暗示了他的意见就是要求和解

His final agreement to meet actually implied that his opinion was to reconcile. 他最终的书面意见其实已经暗示了他的意见是要求和解

His final written opinion actually implied that his opinion was to reconcile.

老总以乐于成全部下而赢得了全部员工的爱戴和尊敬

Because he likes satisfying them, he was admired by all of his employees.

老总因投入全部资产而赢得了全部员工的爱戴和尊敬

Because he invested all of his assets, he was admired by all of his employees. 